\title{
Bioética e direitos além de "humanos": um enfoque filosófico-jurídico contemporâneo
}

\section{Bioethics and rights beyond human: a contemporary-juridical approaches}

\author{
Charles Andrade Froehlich \\ Universidade de Santa Cruz do Sul (UNISC), Santa Cruz do Sul, Rio Grande \\ do Sul, Brasil. \\ caf@unisc.br
}

Resumo: Apresentamos uma abordagem diferenciada dos chamados direitos "humanos", visando ao alargamento de sua perspectiva para adequá-lo às discussões atuais advindas principalmente da filosofia, relativas à ética prática ambiental. Nesse sentido, após algumas anotações iniciais sobre o desenvolvimento da bioética e dos direitos humanos, analisamos, na seqüência, a ética de Peter Singer em defesa dos animais. Ao final, mostramos um balanço da filosofia jurídica contemporânea em face desta expansão da comunidade moral.

Palavras-chave: Bioética. Direitos Humanos. Ética animal. Ética ambiental.

\begin{abstract}
We bring here a different approach on the so called "human" rights, looking for the increase of its perspective to fit it into the actual discussion raised mainly in Philosophy, according to the environmental practical ethics. In this way, after some initial considerations about the bioethics and human rights developments, we analyze the Peter Singer's ethics in defense of animals to finally we show the status of the contemporary law philosophy in face to the expansion of the moral community.
\end{abstract}

Key words: Bioethics. Human Rights. Animal ethics. Environmental ethics. 


\section{Revista Brasileira de Bioética}

Se perscrutarmos em torno de 3000 anos da história humana encontraremos na filosofia grega e na formação do cristianismo as bases éticas e religiosas dos direitos humanos. Prova disso é a formação paulatina da preponderância ou privilégio humano na natureza, derivados da representação humana como imagem e semelhança de Deus, passando-se pelo jusnaturalismo racionalista e a menção e fundamentação da dignidade da pessoa humana, impulsionada por Kant e concretizada, posteriormente, na Declaração Universal dos Direitos Humanos de 1948 (DUDH).

Apesar de toda esta construção histórica, o foco inicial das "dimensões" de direitos humanos situa-se na segunda metade do século XVIII. Neste período, a formação do constitucionalismo moderno e contemporâneo, na esteira de grandes revoluções, ensejou as declarações de direitos e as primeiras constituições escritas, no sentido que lhe emprestamos atualmente. Então, podemos dizer que apesar da "afirmação histórica dos direitos humanos" ter sua origem em criações filosóficas, culturais e religiosas anteriores, a importância, a novidade e as conseqüências do movimento constitucionalista do século XVIII, preponderaram e marcaram de forma indelével e didática o tema dos direitos humanos.

O presente estudo analisa dois temas - bioética e direitos humanos - que permitem inferir na admissão contemporânea de que as demandas de direitos derivadas do desenvolvimento técnico-científico ou da biotecnologia pertencem à chamada 4 a "dimensão" de direitos humanos.

A primeira dimensão de direitos humanos corresponde ao momento inicial do constitucionalismo, aos direitos individuais como vida e liberdade. A tradição afirma que nesse estágio temos a prevalência ou a instauração de uma posição do indivíduo contra o Estado, exigindo condutas negativas deste, ou seja, para preservar a liberdade o Estado deve não fazer uma série de atos que violem esta liberdade. Enfim, o valor liberdade prepondera, a liberdade na perspectiva do indivíduo, ponto de vista comum ao nascente Estado Liberal clássico e aos documentos-chave desse período.

A segunda dimensão de direitos humanos surge após o advento das exigências de direitos sociais, principalmente devido aos abusos decorrentes da dita revolução industrial e as conseqüentes revolu- 
ções socialistas (1917), e pode ser exemplificado com a criação da Organização Internacional do Trabalho (OIT), em 1919. O valor característico deste período é, então, a igualdade. A perspectiva e a demanda apresentadas são outras ou, no mínimo, demonstram esta tendência, preconizando a historicidade dos direitos humanos, apontada por Norberto Bobbio (1). Os direitos humanos são fruto da necessidade de uma época e de uma sociedade; à medida em que surgem novas formas de abusos ou violências à dignidade ou qualidade de vida, cresce a exigência pelo reconhecimento e tutela destes novos direitos.

A terceira dimensão origina-se da chamada internacionalização dos direitos humanos a partir, propriamente, da DUDH, a qual reconhece formalmente a dignidade do ser humano e a autodeterminação dos povos. Não há mais o predomínio da individualidade e, isto sim, da coletividade. Observa-se a ascensão dos direitos coletivos, pertencentes a uma nação ou a todos os membros de uma comunidade. A matriz desta dimensão é a solidariedade. Temos como grandes exemplos, o direito ao desenvolvimento e ao meio ambiente $(2 ; 3)$. A tradição, refém de uma estética, faz menção aos ideais colocados já pela Revolução Francesa - liberté, egalité, fraternité - para se referir a este tema clássico das dimensões de direitos humanos.

Os direitos humanos são, portanto, fruto da história. Ao longo do século XX tivemos um crescimento vertiginoso da tecnologia, a qual possilibitou uma série de procedimentos médicos, biomédicos, manipulações genéticas que geraram, por exemplo, os transplantes de órgãos, a reprodução humana assistida, a clonagem, as sementes e animais geneticamente modificados. No fundo, está em questão o sempre considerado e primordial direito à vida digna, mas as fontes de ofensas são novas, o que, acarreta nova demanda. Surge então a "quarta dimensão" de direitos humanos, a qual corresponde a demandas e instrumentos normativos que tutelam estes novos direitos de "manipulação genética", como aponta Bobbio. 


\section{Bioética: noções, causas e desenvolvimento}

Determinados acontecimentos da década de 1960 marcaram o nascimento da bioética: a primeira seção de hemodiálise feita pelo Dr. Belding Scribner e a conseqüente atuação do Comitê de Seattle (decidindo "quem vive e quem morre"); as pesquisas médicas com negros e pobres que impulsionaram a elaboração de códigos de ética (Caso Tuskegee), entre outros $(4)^{1}$. Entretanto, o conteúdo do que hoje entendemos como bioética vem sendo desenvolvido há muito tempo, uma vez que os conhecidos princípios da bioética principialista, como a beneficência e não-maleficência buscam sua fonte em Hipócrates; refletindo também o repúdio aos abusos cometidos por profissionais da saúde durante a Segunda Guerra Mundial. Fica claro que assim que, como os direitos humanos, a bioética é uma construção histórica que vai lapidando-se, sendo, finalmente nominada e conceituada. Deve-se ao oncologista americano Van Rensselaer Potter, já na década de 1970, as primeiras noções de bioética, tais como: "ciência da sobrevivência", aliando conhecimento biológico e valores humanos.

Mas é pertinente perguntar: quais as causas possíveis da bioética ou quais as inovações e exigências que prepararam o terreno para a ascensão da bioética? Podemos resumir em duas causas básicas: a) o próprio desenvolvimento dos direitos humanos, principalmente a já aludida "internacionalização dos direitos humanos" a partir de 1948, após a dimensão dos danos provocados à pessoa humana na Segunda Guerra Mundial; b) o desenvolvimento técnico-científico, o qual possibilitou tanto descobertas como acelerou técnicas e procedimentos relativos à saúde e ao tratamento das pessoas: a "medicalização da vida" (5)².

O período que começa em 1948 e vem até os nossos dias tornouse conhecido como o da internacionalização dos direitos humanos. A diferença específica foi a criação da Organização das Nações Unidas (ONU) em 1945 e a respectiva Carta da ONU, a qual, por sua vez, originou a DUDH em 1948. O que se destaca neste período? A reafir-

\footnotetext{
${ }^{1}$ Azevedo (2002) afirma que a "alocação de recursos escassos" foi um dos fenômenos que relativizou a tradição hipocrática e inaugurou a bioética: na esteira de uma tecnologia (hemodiálise), houve a necessidade de triagem dos pacientes.

2 Diniz (2001) traça uma série muito maior de "causas".
} 
mação dos direitos humanos construídos até aquele momento, dada a característica da indivisibilidade e a vinculação da comunidade internacional às normas e objetivos delineados pelo conjunto de documentos que começa a se formar como, por exemplo, a DUDH e os dois pactos de 1966, os quais formam a Internacional Bill of Rights. Enfim, há a explicitação e a consolidação de uma consciência ética universal (6), revelada no próprio preâmbulo da DUDH mediante a inserção da dignidade como base axiológica do sistema dos direitos humanos. Paulatinamente, à medida que o aludido sistema vai-se formando, temos a participação dos Estados na ordem internacional, a inter-relação do sistema com as Constituições dos Estados, o crescente conhecimento e informação sobre este conjunto de direitos de todos, sem qualquer restrição ou discriminação. Bobbio afirma que, pela primeira vez, temos uma espécie de consenso internacional escrito e positivado sobre direitos humanos, o que reflete uma espécie de síntese dialética entre o jusnaturalismo e o juspositivismo.

A relação com a bioética é clara: no momento em que temos direitos humanos universais, os abusos, lesões e ofensas à dignidade da vida no âmbito das áreas da saúde tornam-se mais evidentes e suscetíveis de proteção. Há uma resposta neste sentido. De outra forma, podemos afirmar que ambas as construções teóricas se tocam num ponto: a ética. Na teoria dos direitos humanos, a história da ética é revista para chegarmos ao que foi chamado de "consciência ética universal" (7). Nesta revisão histórica surgem também dois conceitos fundamentais: pessoa e dignidade. Quem é o sujeito de direitos? Como mudou a forma de vermos e entendermos este sujeito de direitos, ao longo do tempo? Comparato nos apresenta um bom histórico: desde a máscara grega de teatro e a expressão personare $=$ pessoa - o papel que representa - passando pela busca da substância racional (Boécio), o fim em si mesmo (Kant) até o ser-no-mundo heideggeriano. Desta evolução conceitual surge a noção de dignidade. Interessante observar que, num primeiro momento, a noção de dignidade (dignitas) é aplicada a status ou cargo, função, e, na voz de Kant, torna-se um atributo do ser racional e autônomo, o qual não tem preço:

"No reino dos fins, tudo tem ou um preço ou uma dignidade. Quando uma coisa tem preço, pode ser substituída por algo equi- 
valente; por outro lado, a coisa que se acha acima de todo o preço, e por isso não admite qualquer equivalência, compreende uma dignidade" (8).

Também deste filósofo, o pensamento de que os seres racionais são pessoas, fins em si mesmos, "algo que não pode ser empregado como simples meio e que, portanto, nessa medida, limita todo o arbítrio (senod, portanto, objeto de respeito)" (9).

A bioética surge, então, frente ao rápido desenvolvimento tecnológico e aos novos dilemas surgidos, devendo-se destacar que se trata de uma ética aplicada, ou seja, passa-se à aplicação prática de teorias filosóficas no âmbito das ciências da vida e da saúde. Observe-se os exemplos dos comitês de ética em pesquisa e dos comitês de bioética dos hospitais, estes últimos contemporâneos ao nascimento oficial da bioética. Há método, discussão e pareceres sobre situações e decisões envolvendo, principalmente a vida: início e fim da vida (aborto e eutanásia); pesquisa com seres humanos; reprodução humana assistida e a questão dos embriões excedentários; o mapeamento genético, a manipulação de células germinais e a clonagem. O velho direito à vida está frente a novos desafios.

Das suas origens até os nossos dias, a bioética passou por várias fases ou períodos. Desde o período de consolidação como disciplina até investigações recentes sobre os tipos e os fundamentos da bioética. Um exemplo claro desta transição é o uso dos princípios fundamentais da bioética: beneficência e não-maleficência; autonomia e justiça, os quais eram, primeiramente, como se disse, princípios fundamentais ou gerais da bioética, derivados do Relatório Belmont. Após críticas sérias à elaboração e à admissão destes princípios gerais, ou se deixa de lado os princípios ou se qualifica esta bioética de "principialista". Nesta outra fase, temos uma pluralidade de "bioéticas". Em outras palavras, precisamos adjetivar a bioética para sabermos de qual tipo de bioética estamos falando. Este adjetivo depende de vários fatores, como: a) o país de origem e a tradição: européia, americana, latinoamericana; b) o método ou o paradigma de abordagem: principialista; liberal; cuidado.

Em uma breve passagem por vários autores, vemos o seguinte: Diniz e Guilhem falam em "abordagens": historicista; temática e fi- 
losófica (10). Engelhardt fala em bioética "plural" devido à impossibilidade de uma "moralidade secular canônica essencial" em face do pluralismo da pós-modernidade. Não há uma bioética geral, de aceitação geral em face dos inúmeros conflitos morais das comunidades específicas (11). Barchifontaine assinala os paradigmas da bioética: principialista, liberal, cuidado, das virtudes (12) e Guy Durand traz as abordagens norte-americana e latina (13).

Em suma, a bioética, conforme o seu conceito geral, envolve uma variedade de metodologias éticas num contexto multidisciplinar. Mas, aqui, podemos assinalar que em qualquer abordagem ou classificação da bioética está presente a temática dos direitos humanos e dos direitos dos animais, sendo que ambos podem ser articulados mediante a observação acurada de outro tema caro a bioética, desde sua origem: o ambiente.

\section{A consideração ética dos "seres sencientes": a ética de Singer}

O filósofo australiano Peter Singer tornou-se mundialmente conhecido na década de 1970 quando publicou a obra Animal liberation (14), denunciando a tortura, os maus-tratos e o sofrimento dos animais confinados em fazendas industriais e destinados ao abate e à alimentação humana. Esta obra, na verdade, é a culminação do movimento desenvolvido pelo Grupo de Oxford, o qual produziu várias obras no sentido da defesa dos animais ${ }^{3}$.

O projeto ético de Singer foi além com a publicação da obra Practical ethics, em 1979. Utilizando-se de noções desenvolvidas em Animal liberation, o autor consolida sua proposta de inclusão dos animais, sencientes na comunidade moral, a partir do princípio básico e fundamental de sua ética: o princípio da igual consideração de interesses. Singer afirma que a ética pretende um ponto de vista universal, portanto não se admite nenhuma justificativa baseada estritamente em interesses pessoais (15a).

\footnotetext{
${ }^{3}$ Conforme Felipe (2001), esse grupo foi formado, entre outros, por Richard D. Ryder (criador da expressão "especismo"; autor de Victims of science e Animal revolution), Stanley e Rosalind Godlovitch e John Harris, autores de Animals, men and morals (Oxford 1971) e Stephen Clarke, autor de The moral status of animal (1977).
} 


\section{Revista Brasileira de Bioética}

Dessa forma, quando vamos tomar uma decisão, devemos levar em consideração os interesses de todos os envolvidos, sem nenhum privilégio concernente ao sexo, raça, inteligência ou espécie. Além disso, devemos considerar também os interesses de todos os seres capazes de sentir dor e prazer, felicidade e sofrimento. Estes seres são denominados "seres sencientes", seres que sentem, ou seja, animais humanos e não humanos. Para Singer, enfim, o argumento para estender o princípio da igualdade além da nossa própria espécie é simples, visto que a nossa preocupação com os outros não deve depender de como são ou que aptidões possuem: as diferenças de cor, inteligência e espécie não dão direito de exploração (16a).

Singer, portanto, "extrapola" ou "revisa" o antropocentrismo ao defender a igualdade de todos os seres sencientes. Dessa maneira, todos os animais, humanos e não humanos fazem parte da comunidade moral e devem ter seus interesses igualmente considerados. Não podemos infligir qualquer tipo de sofrimento desnecessário e inútil aos membros desta comunidade moral para beneficiar interesses menores como comer uma carne mais macia ou mais gostosa. Se existem alternativas alimentícias; se o custo ambiental para a produção intensiva de carne (de aves e suínos, principalmente) é altíssimo; se, para obter este tipo de carne, causamos dor e sofrimentos inomináveis; então estamos infringindo o princípio da igualdade de interesses, visto que estamos menosprezando a dor e o sofrimento destes seres visando a um "benefício" discutível.

Enfim, a ética de Singer fornece-nos uma base para a discussão sobre a ética ambiental, porque: a) critica o paradigma antropocêntrico: Singer, nesse e em outros momentos $(17)^{4}$, contesta as correntes filosóficas e religiosas que defendem o homem como o senhor absoluto da natureza; o ser privilegiado que domina e usufrui ilimitadamente de todos os outros seres; b) ao defender a igualdade dos seres sencientes, Singer alerta-nos também para os graves problemas ambientais derivados da criação intensiva de animais para o abate, quais sejam, a produção e o consumo de alimentos (grãos) para os

\footnotetext{
${ }^{4}$ Ver o capítulo 10 de Ética prática (2002 a) sobre o meio ambiente e o texto "Em lugar da velha ética", publicado, no Brasil, na coletânea de artigos sob o título Vida ética (Singer, 2002b).
} 
animais confinados; a água para o consumo e lavagem destes animais e a energia elétrica necessária utilizada $(18 ; 19)$; c) combate a desigualdade sócio-econômica; d) propõe, especificamente, a discussão sobre os valores ambientais.

\section{"Em lugar da velha ética"}

Quando Singer debate sobre os valores em ética ambiental, ele afirma que estabelecer plausivelmente uma ética para além dos seres sencientes é uma tarefa muito difícil e, enfim, se mantém na sua argumentação conforme o parâmetro ético dos animais sencientes, humanos e não humanos, presentes e futuros. A ética que tínhamos (de raiz antropocêntrica) comportava princípios contrários à sustentabilidade, de tal forma que é necessário desenvolver uma nova ética ambiental (20a).

Na obra Rethinking life and death de 1994, depois da $2^{\mathrm{a}}$ edição de Ética prática em 1993, Singer apresentou o texto "Em lugar da velha ética", no qual elenca os "mandamentos" da velha e da sua nova ética. É possível pensar alguns destes "mandamentos" na abordagem de uma ética ambiental ${ }^{5}$. Segundo ele, a velha ética era pautada por:

"Segundo velho mandamento: jamais tire intencionalmente a vida de um ser humano inocente; Quinto velho mandamento: trate toda a vida humana como se sempre fosse mais valiosa que qualquer vida não-humana"(21).

A nova ética proposta por Singer altera tais pressupostos. Para fundamentar uma ética ambiental, esses novos mandamentos são diretamente aplicáveis e podem ser considerados: "assuma a responsabilidade pelas conseqüências de suas decisões" e "não discrimine com base na espécie". O $5^{\circ}$ novo mandamento assumiu a característica central no pensamento de Singer e pode ser um axioma de toda sua ética, uma vez que propõe um deslocamento de foco, de uma

\footnotetext{
${ }^{5}$ Para as devidas expansões e esclarecimentos, remetemos o leitor para os capítulos 2 a 6 de Ética prática (Singer, 2002a) e para o texto "Em lugar da velha ética" (Singer, 2002bB).
} 


\section{Revista Brasileira de Bioética}

perspectiva antropocêntrica forte e sagrada para uma perspectiva não antropocêntrica (ou antropocêntrica "fraca") e sem privilégios fundados na espécie ("especismo"). A partir deste "mandamento" é que se reconhece a igualdade de todos os seres sencientes. Assim, todos os seres capazes de sentir dor e prazer, sofrimento e felicidade devem ser tratados da mesma forma. Singer, então, está trazendo todos os animais sencientes para a comunidade ética e, por conseqüência, os seus interesses devem ser considerados.

O $2^{\circ}$ dos "mandamentos" elencados trata diretamente da dificuldade de distinção entre matar e deixar morrer. Singer está procurando definir, esclarecer que a distinção não se sustenta em ter-mos de conseqüências das nossas ações, em sentido amplo. O autor diz claramente que não está dizendo que "matar" é equivalente a "deixar de salvar", mas, sim, "ver com mais seriedade nosso fracasso em fazer o necessário por aqueles cujas vidas poderíamos salvar sem grandes sacrifícios de nossa parte" (21b). Em suma, há um chamado à responsabilidade dos mais ricos (países e pessoas). Em termos de ética ambiental, sabemos que a conscientização e a proteção necessária e relativa ao meio ambiente passa pela educação ambiental e pela solidariedade entre os povos, com a conseqüente eliminação ou diminuição da miséria. Temas como superpopulação, tratamento do lixo e esgotos, desmatamentos, estão diretamente relacionados com a capacidade financeira dos Estados respectivos. Singer está alertando para a necessidade de uma melhor distribuição de renda ou uma diminuição da desigualdade entre ricos e pobres mediante a adoção de uma vida sem extravagâncias, sem excessos e supérfluos ${ }^{6}$.

\section{Os direitos ambientais: animais na era do pós-positivismo}

Na teoria e na filosofia jurídicas contemporâneas, costuma-se destacar três grandes períodos pelos quais passou o Direito: período jusnaturalista; período positivista e o período pós-positivista. É claro que corremos o perigo da generalização demasiada, mas é possível destacar, na história do direito, momentos de ascensão e queda dos dois primeiros períodos e vivemos a busca da caracterização do direi-

\footnotetext{
6 "Ricos e pobres" é o capítulo de Ética prática que trata do tema (Singer, 2002a).
} 
to contemporâneo. Conforme um conjunto de autores, mormente do direito constitucional, presenciamos a era do pós-positivismo.

A expressão carrega mais a denotação do período do que o significado que ela comporta. Ou seja, após a consolidação e o apogeu da perspectiva positivista do direito e todos os seus problemas (início do século XIX - metade do século XX), surgiram as respectivas críticas a essa perspectiva, especialmente da metade do século XX em diante. No mesmo período, tivemos a consolidação do constitucionalismo contemporâneo, a partir de uma série de Constituições, que contempla uma base principiológica forte. Na esteira deste movimento, sólida doutrina se formou trazendo novos conceitos de princípio; a distinção entre regras e princípios; a normatização dos princípios, bem como a caracterização dos princípios.

A doutrina afirma que o período pós-positivista se comporta como uma síntese dos grandes períodos anteriores ou como superação do grande dualismo jusnaturalismo-juspositivismo e busca uma possível caracterização do pós-positivismo. Essa caracterização destaca-se ao dizer que o direito contemporâneo contemplou a normatividade dos princípios constitucionais. Depois de serem vistos como princípios gerais e abstratos, sem verdadeira aplicação (jusnaturalismo) ou de serem utilizados de maneira subsidiária (juspositivismo), os princípios adquirem o status de norma e, mais do que isso, "norma constitucional", colocados no ponto máximo do ordenamento, aspergindo uma série de valores (de ética e justiça) e funcionando como uma "bússola" interpretativa do direito contemporâneo.

Podemos destacar que o conceito e a aplicação dos princípios constitucionais propõem uma caracterização do direito contemporâneo, tanto que encontramos a expressão Direito Principial (22). Enfim, o que encontramos de novo neste período é um retorno da ética e da justiça ao ordenamento jurídico, sob a forma de princípios constitucionais, os quais devem ser aplicados juridicamente a partir da hermenêutica constitucional e da filtragem constitucional. Essa conjuntura conforma o constitucionalismo contemporâneo.

Nossa incursão pelo pós-positivismo visa a destacar justamente esses fatores: a) retorno da valoração ética ao ordenamento jurídico; b) tal valoração está inserida sob a roupagem de norma constitucional; c) estes princípios devem servir de guia interpretativo do direito na 


\section{Revista Brasileira de Bioética}

sociedade democrática. Especificamente, os princípios fundamentais da Constituição Federal de 1988 (CF), arts. $1^{\circ}$ a $4^{\circ}$, assim como alguns direitos fundamentais localizados nos artigos $5^{\circ}$ e $6^{\circ} \mathrm{e}$, para a presente abordagem, a tutela constitucional do meio ambiente (art. 225).

Ronald Dworkin, em um dos grandes textos deste período, afirma que "princípio" é "um padrão que deve ser observado", em função de "uma exigência de justiça ou eqüidade ou alguma outra dimensão da moralidade". Este jurista busca a aplicação da idéia de uma "filosofia constitucional", afirmando, inclusive que:

"A Constituição funde questões jurídicas e morais, fazendo com que a validade de uma lei dependa da resposta a problemas morais complexos, como o problema de saber se uma determinada lei respeita a igualdade inerente a todos os homens" (23).

Mediante a aplicação da doutrina estabelecida do pós-positivismo jurídico e sua complementar fundamentação ético-filosófica, defendemos o direito à vida como sustentáculo democrático-ambiental que deve ser reconhecido de maneira ampla, a todos os seres vivos e, especialmente, a todos os seres sencientes, os quais, segundo Singer, são capazes de sentir dor e prazer; felicidade e sofrimento.

\section{Exemplos de casos brasileiros}

Na nossa perspectiva, o leading case brasileiro que veio a integrar a consideração ética dos animais com o pós-positivismo foi o acórdão do Supremo Tribunal Federal (STF) sobre a "farra do boi". Quatro associações e órgãos de defesa dos animais ajuizaram ação civil pública em face do Estado de Santa Catarina com o escopo de forçá-lo a proceder à proibição daquela festa. No acórdão os ministros discutiram qual o preceito constitucional prevaleceria no caso concreto: se aquele referente à manifestação cultural (arts. 215216) ou aquele referente à tutela constitucional do meio ambiente (art. 225). Anote-se que o fundamento do recurso extraordinário era justamente a ofensa ao art. $225 \S 1^{\circ}$, VII da Carta Magna em vigor. Existem momentos marcantes no acórdão que vale sublinhar e comentar. $\mathrm{O}$ primeiro deles diz respeito à repulsa dos julgadores ao que 
foi chamado "consideração metajurídica das prioridades", em relação à qual o Ministro Relator Francisco Resek afirmou que entre as tentações que:

“...podem rondar o julgador e que devem ser repelidas para um correto exame de controvérsia são, primeiro, a consideração metajurídica das prioridades: porque, num país de dramas sociais tão pungentes, há pessoas preocupando-se com a integridade física ou com a sensibilidade dos animais? Esse argumento é de uma inconsistência que rivaliza com sua impertinência. A ninguém é dado o direito de estatuir para outrem qual será sua linha de ação, qual será, dentro da Constituição da República, o dispositivo que, parecendo-lhe ultrajado, deva merecer seu interesse e sua busca de justiça. De resto, com a negligência no que se refere à sensibilidade de animais anda-se meio caminho até a indiferença a quanto se faça a seres humanos. Essas duas formas de desídia são irmãs e quase sempre se reúnem, escalonadamente" (24).

O segundo ponto relaciona-se ao conflito constitucional entre o direito à manifestação cultural e a tutela constitucional dos animais. Sobre isso a Constituição assegura, no art. 215 “... o pleno exercício dos direitos culturais e o acesso às fontes da cultura nacional". Não é possível deixar de compreender esse dispositivo na perspectiva dos princípios maiores da Constituição, dos fundamentos básicos da organização da República, que estão no art. 1. da Lei Maior. Há, entretanto, outra, de assento constitucional também, com base no art. 225 da Lei Magna, invocada no recurso. Reza o art. 225:

"Art. 225. Todos têm direito ao meio ambiente ecologicamente equilibrado, bem de uso comum do povo e essencial à sadia qualidade de vida, impondo-se ao Poder Público e à coletividade o dever de defendê-lo e preservá-lo para as presentes e futuras gerações.

$\S 1 .^{\circ}$ Para assegurar a efetividade desse direito, incumbe ao Poder Público:(...)

VIl - proteger a fauna e a flora, vedadas, na forma da lei, as práticas que coloquem em risco sua função ecológica, provoquem a extinção de espécies ou submetam os animais a crueldade" (25). 


\section{Revista Brasileira de Bioética}

Nesses dispositivos do art. 225 há, sem dúvida, nítida integração com os princípios e valores dos arts. $1 .^{\circ}$ e $3 .^{\circ}$ da Constituição, no que concerne aos princípios fundamentais da República. Segundo o já citado Ministro Resek:

“Entendo, dessa maneira, queos princípios evalores da Constituição em vigor, que informam essas normas maiores, apontam no sentido de fazer com que se reconheça a necessidade de se impedirem as práticas, não só de danificação ao meio ambiente, de prejuízo à fauna e à flora, mas também que provoquem a extinção de espécies ou outras que submetam os animais a crueldade. A Constituição, pela vez primeira, tornou isto preceito constitucional, e, assim, não parece que se possam conciliar determinados procedimentos, certas formas de comportamento social, tal como a denunciada nos autos, com esses princípios, visto que elas estão em evidente conflito, em inequívoco atentado a tais postulados maiores"(26).

Este voto final demonstra a verdadeira ponderação de princípios constitucionais conflitivos, afirmando-se qual preponderava no caso, optando-se por uma hermenêutica constitucional, na qual se destaca o conjunto de princípios que contém os preceitos éticos fundamentais, ou seja, o art. $1^{\circ}$ e incisos e o art. $3^{\circ}$ da CF, combinados com o art. 225 da mesma CF. Os artigos $1^{\circ}$ e $3^{\circ}$, como sabemos, fazem parte dos princípios fundamentais da $\mathrm{CF} / 88$, os quais indicam os valores da cidadania, da dignidade, da justiça e da não-discriminação.

A República Federativa do Brasil que se constitui como Estado Democrático de Direito, estabelece a convivência digna e justa, realizada com práticas de solidariedade, tolerância e bem-estar. O Ministro julgador conclui de maneira exemplar ao relacionar o art. 225 da CF com os princípios fundamentais: ora, a CF não é feita de artigos isolados e desconexos, pelo contrário, ainda mais na temática afeita ao meio ambiente como bem coloca o caput do art. 225 "bem de uso comum do povo e essencial à sadia qualidade de vida... para as presentes e futuras gerações..." (27). Não podemos, de maneira alguma, fazer prevalecer uma prática cultural cruel, violenta e sanguinária em benefício meramente da tradição! É praticamente como se defendêssemos o trabalho escravo em algumas regiões brasileiras 
porque a cultura colonial escravocrata ainda é muito presente. Esta analogia vem bem a calhar se pensarmos conforme o princípio da igual consideração de interesses dos seres sencientes, na perspectiva de Singer. Em vez da prática cultural cruel, então, deve prevalecer a vida pacífica.

Laerte Fernando Levai, doutrinador e membro do Ministério Público do Estado de São Paulo (MP/SP) lembra que o art.170 da CF/88 trata da ordem econômica e financeira, inclusive, traz como princípio geral a "defesa do meio ambiente" (art.170, VI). A hermenêutica constitucional leva-nos, então, a considerar que o interrelacionamento dignidade-vida-saúde-justiça-ambiente deve preponderar e atuar como semente interpretativa do sistema jurídico. Este autor é conhecido por ser um dos pioneiros na promoção de ações civis públi-cas contra circos e rodeios, questionando os maus-tratos, abusos e crueldade para com os animais. Recentemente, em uma destas ações, Laerte Levai afirmou:

"que o espírito protecionista do direito ambiental não se deve ater somente ao viés ecológico, que classifica a fauna como recurso natural ou bem difuso, tampouco se curvar a preceitos de ordem econômica e laborativa, mas viger em função daquilo que a Constituição preconiza no art. 225, § 1. ․, VII: vedação à crueldade. Ora, se a norma constitucional trata de uma prática correlata à desumanidade - crudelis, que, em sentido próprio, é aquele 'que gosta de fazer correr sangue, e daí: cruel, desumano, insensível' (...), ou, então, 'qualidade de cruel ou o ato cruel' (...) - erigindo o dever de proteção aos animais em relevante questão moral, foi porque reconheceu que um ser vivo, longe de constituir mera rés ou bem de consumo, é capaz de vivenciar dores, aflições, angústias e sofrimentos. Esse dispositivo supremo, [tanto] na Constituição Federal (art. 225) (...) deve preponderar sobre aqueles outros relacionados ao labor, à economia ou à propriedade, porque o bem supremo de qualquer criatura é a vida" (28).

A relação com a ética singeriana torna-se bastante clara: a CF adotou o princípio ético maior de proteção à vida digna e busca a instituição de uma sociedade mais justa e igualitária ( $\left.\operatorname{art} .3^{\circ}, \mathrm{I}\right)$, na qual 


\section{Revista Brasileira de Bioética}

deve preponderar a vida, em detrimento do lucro e da propriedade, tutelando, dessa forma os animais humanos e não humanos, resguardando-os de tratamentos cruéis (aflições, dores, sofrimentos). Enfim, o mandamento constitucional:

“...não se limitou em garantir a variedade das espécies ou a função ecológica da fauna. Adentrou no campo da moral. Ao impor expressa vedação à crueldade para com os animais, como que admitindo a prática da maldade e do sadismo humano sobre outras criaturas, nosso legislador constitucional admitiu a possibilidade de o animal ser considerado sob a perspectiva ética e, portanto, sujeito jurídico passível de tutela mediante representação processual adequada (substituído, no caso, pelo Ministério Público, a quem toca a proteção jurídica dos animais)" (29).

Revela-se então uma característica forte do pós-positivismo: a hermenêutica constitucional (ou a filtragem constitucional), ou seja, a "preponderância" dos princípios máximos (fundamentais) da Carta da República. Realmente, o intérprete jurídico contemporâneo passa a ver a aplicação do direito sob a perspectiva dos princípios e direitos fundamentais, tornando-os normas efetivas. Nesse sentido, todo o ordenamento jurídico deve ser observado a partir dos princípios supremos da $\mathrm{CF}$, que contêm objetivos éticos e assinalam um tipo de convivência entre humanos e não humanos, a qual deve ter como grande objetivo a consolidação do Estado Democrático de Direito. $\mathrm{O}$ art. $1^{\circ}$ da CF assinala que este Estado Democrático de Direito se fundamenta, entre outros, na cidadania e na dignidade (incisos II e III). O art. $3^{\circ}$ aponta os objetivos da República Federativa do Brasil: I construir uma sociedade livre, justa e solidária e IV - promover o bem de todos, sem preconceitos de origem, raça, sexo, cor, idade e quaisquer outras formas de discriminação. Ora, sob a ótica apresentada, conforme o momento do pós-positivismo, com as sua características da normatividade dos princípios constitucionais, do conteúdo ético dos princípios e da hermenêutica constitucional, podemos muito bem admitir e conceber as interpretações acima mencionadas. 


\section{Direitos não só humanos}

Cabe mencionar, ainda, outro autor que fundamenta uma teoria de direitos morais para os animais: Tom Regan. Destaca-se o seu princípio da coerência que exige a mesma observação e tratamento no que se refere aos direitos humanos e aos direitos dos animais. Seja porque lado se observe, seja pela igualdade, seja pelo bem-estar, a mesma argumentação utilizada no primeiro caso deve ser expandida para o segundo.

Como vimos, na primeira parte, os direitos humanos são fruto de uma construção e exigências históricas, as quais buscaram na filosofia sua fundamentação. Regan, divergindo da argumentação de Singer sobre "interesse", defende os direitos dos animais, afirmando que todo o discurso dos direitos humanos deve também ser aplicado aos animais por uma questão de coerência. Ora, se não deve haver discriminação, se não há exigência de determinadas características (autoconsciência; racionalidade etc.) para a admissão de direitos fundamentais, se todos têm que viver dignamente e buscar o bem-estar, por uma questão de coerência, devemos estender aos animais nãohumanos esses direitos. Felipe afirma que:

"O discurso dos direitos, de acordo com Regan, e diversamente de Singer, deve ser empregue, por uma questão de coerência, no mínimo, na defesa dos animais, e, possivelmente, na defesa de outras formas de vida (...). Regan não afirma nem nega que outros seres tenham direitos, apenas insiste em que, por uma questão de coerência com o discurso que defende direitos para os humanos, e devido ao sentido que tal discurso institui, deve-se ampliar o âmbito de aplicação do mesmo para abranger os atos humanos que afetam seres dotados da capacidade de sofrer (...)" (30).

Para Regan, os animais são "sujeitos-de-uma-vida", portanto, merecedores de respeito moral; possuem "valor inerente" (31); o sofrimento ou a capacidade de sentir dor lhes permitem usufruir de bemestar e uma vida boa sem limitações de liberdade, alimento e sem agressões à integridade física. A coerência, então, reside no fato de que todos os sujeitos-de-uma-vida possuem dignidade, não podem 


\section{Revista Brasileira de Bioética}

ser usados como meios para um fim, possuem valor inerente, são fins em si mesmos. Assim, com base no discurso dos direitos humanos, também não há possibilidade de exclusão dos animais não humanos da comunidade moral.

É interessante apontar como alguns autores que discutiram a expressão "direitos humanos" já se manifestaram nesse sentido. Falamos do constitucionalista brasileiro José Afonso da Silva e o jusfilósofo italiano Norberto Bobbio, respectivamente, nas seguintes passagens:

"Direitos humanos é expressão preferida nos documentos internacionais. Contra ela, assim, como contra a terminologia direitos do homem, objeta-se que não há direito que não seja humano ou do homem, afirmando-se que só o ser humano pode ser titular de direitos. Talvez já não mais assim, porque, aos poucos, se vai formando um direito especial de proteção dos animais" (32);

e

"Olhando para o futuro, já podemos entrever a extensão da esfera do direito à vida das gerações futuras, cuja sobrevivência é ameaçada pelo crescimento desmesurado de armas cada vez mais destrutivas, assim como a novos sujeitos, como os animais, que a moralidade comum sempre considerou apenas como objetos, ou, no máximo, como sujeitos passivos, sem direitos" (33).

\section{Considerações finais}

Existiu um tempo em que as mulheres e pessoas de cor ou etnia diferente eram desconsideradas eticamente ou não tinham direitos. A argumentação ética e os padrões sócio-jurídicos foram, paulatinamente, modificando-se, ampliando-se nesta busca da igualdade: não é o sexo, nem a cor da pele, nem mesmo a situação social ou étnica que devem servir como parâmetro ou limitador para a participação na comunidade moral. A Declaração Universal dos Direitos Humanos de 1948 veio consolidar esse entendimento: toda a pessoa humana é igual em direitos e dignidade, independentemente de raça, cor, sexo, língua, religião, opinião, origem nacional ou social. Até aí nenhuma 
novidade, conhecemos esta história e ainda tentamos implementá-la, é verdade.

O alargamento da igualdade surge a partir da definição do que seja "interesse" ou de quem tem "interesse". Os filósofos da Animal ethics afirmam que possui "interesse" todo o ser que sente, ou seja, é capaz de sentir dor e prazer, felicidade e sofrimento. E todo o ser que tem interesse deve fazer parte da comunidade moral, sem qualquer tipo de discriminação. A discriminação feita a partir da espécie é denominada "especismo" (speciesism) e consiste no entendimento de que os animais não humanos existem para servir aos interesses humanos das mais variadas formas, tais como: transporte; cobaias de qualquer pesquisa e, principalmente, para a alimentação.

Além e longe de qualquer discriminação (sexual, intelectual, racial, especista), o princípio da igual consideração dos interesses de todos os animais sencientes estabelece um novo e melhor relacionamento entre o animal humano e o animal não humano. A partir dele, com um passo a frente, vislumbramos um novo relacionamento também entre homem e ambiente. Seja na linguagem específica da ética, seja na linguagem dos direi-tos, temos toda uma perspectiva filosóficojurídica contemporânea que ampliou o círculo da comunidade ética, saindo dos limites do estritamente "humano" ou "para o humano" e trouxe a preocupação com o outro (humanos e não humanos, presentes e futuros) e, nessa relação, a compreensão ambiental.

Enfim, a história dos direitos humanos e da bioética e a situação contemporânea confluem para a preocupação e consideração da vida digna em um sentido coletivo e ambiental por uma questão que se tornou, tragicamente, de "sobrevivência". Vale lembrar as origens da bioética como "ciência da sobrevivência" e considerar que neste relacionamento não há conduta ou atitude eticamente "neutra". Na escolha da alimentação, dos esportes e da vida confortável que a sociedade contemporânea propõe, estão envolvidas questões cruciais de ética ambiental. Precisamos estar atentos a nossa conduta nestes relacionamentos e assumir a responsabilidade pelo que fazemos e deixamos de fazer.

Este texto apresenta resultado parcial de pesquisa financiada pela Universidade de Santa Cruz do Sul (UNISC), Estado do Rio Grande do Sul. 


\section{Revista Brasileira de Bioética}

\section{Referências}

1. Bobbio, N. A Era dos direitos. Rio de Janeiro, Campus, 1992.

2. Bonavides, P. Curso de direito constitucional. São Paulo, Malheiros, 2002.

3. Bobbio, N. Op. cit.,1992.

4. Azevedo, MAO. Bioética fundamental. Porto Alegre: Tomo Editorial, 2002.

5. Diniz, MH. O estado atual do biodireito. São Paulo, Saraiva, 2001.

6. Comparato, FK. A afirmação histórica dos direitos humanos. São Paulo, Saraiva, 2001.

7. . Op. cit., 2001.

8. Kant, I. Fundamentação da metafísica dos costumes. São Paulo, Martin Claret, 2003.

9. Op. cit., 2003.

10. Diniz, D \& Guilhem, D. O que é bioética. São Paulo, Brasiliense, 2002.

11. Engelhardt, TJr.. Fundamentos da bioética.São Paulo, Loyola, 1998.

12. Barchifontaine, CP. Bioética e início da vida: alguns desafios. São Paulo, Idéias e Letras/Centro Universitário São Camilo, 2004.

13. Durand, G. Introdução geral à bioética: história, conceitos e instrumentos. São Paulo, EDUSC, 2003.

14. Singer, P. Libertação Animal. Porto Alegre, Lugano, 2004.

15. Singer, P. Ética Prática. São Paulo, Martins Fontes, 2002 a.

16. Op. cit., 2002 a.

17. Op. cit., $2002 \mathrm{~b}$.

18. Felipe, ST. Da Igualdade. Peter Singer e a defesa ética dos animais contra o especismo. Philosophica - Revista de Filosofia da Universidade de Lisboa. Lisboa, 17/18, Set. 2001. pp. 25-26.

19. Direitos animais. O recurso à analogia e a exigência do princípio da coerência na ética de Tom Regan. www.vegetarianismo.com.br. Acesso em 3 de maio de 2004.

20. Singer, P. Op. cit., 2002 a.

21. Op. cit., 2002b.

22. Bonavides, P. Op. cit., 2002.

23. Dworkin, R. Levando os direitos a sério. São Paulo, Martins Fontes, 2002.

24. Brasil. Supremo Tribunal Federal. Meio Ambiente. Crueldade a animais. "Farra do boi". Relator Ministro Francisco Rezek. Revista dos Tribunais 753, jul.1998.pp.101-15.

25. Brasil. Senado Federal. Constituição da República Federativa do Brasil. Brasília, Senado Federal, 1988.

26. Op. cit.,1998.

27. Op. cit.., 1988.

28. Levai, LF. Abuso e crueldade para com os animais. Exibições circenses. Bichos cativos. Revista de Direito Ambiental. São Paulo, n.31, jul-set. 2003.pp. 207-221.

29. Op. cit., 2003.

30. Felipe, ST. Por uma questão de princípios: alcance e limites da ética de Peter Singer em defesa dos animais. Florianópolis, Fundação Boiteux, 2003.

31. Op. cit., 2003.

32. Silva, JA. Curso de direito constitucional. São Paulo, Malheiros, 2000.

33. Bobbio, N. Op. cit., 1992.

Recebido em 29/11/2005. Aprovado em 12/1/2006. 